\title{
In vitro and in vivo endocrine disrupting effects of the azole fungicides triticonazole and flusilazole
}

Draskau, Monica Kam; Boberg, Julie; Taxvig, Camilla; Pedersen, Mikael; Frandsen, Henrik Lauritz; Christiansen, Sofie; Svingen, Terje

\section{Published in:}

Environmental Pollution

Link to article, DOI:

10.1016/j.envpol.2019.113309

Publication date:

2019

Document Version

Peer reviewed version

Link back to DTU Orbit

Citation (APA):

Draskau, M. K., Boberg, J., Taxvig, C., Pedersen, M., Frandsen, H. L., Christiansen, S., \& Svingen, T. (2019). In vitro and in vivo endocrine disrupting effects of the azole fungicides triticonazole and flusilazole. Environmental Pollution, 255(Part 2), [113309]. https://doi.org/10.1016/j.envpol.2019.113309

\section{General rights}

Copyright and moral rights for the publications made accessible in the public portal are retained by the authors and/or other copyright owners and it is a condition of accessing publications that users recognise and abide by the legal requirements associated with these rights.

- Users may download and print one copy of any publication from the public portal for the purpose of private study or research.

- You may not further distribute the material or use it for any profit-making activity or commercial gain

- You may freely distribute the URL identifying the publication in the public portal 


\section{Journal Pre-proof}

In vitro and in vivo endocrine disrupting effects of the azole fungicides triticonazole and flusilazole

Monica Kam Draskau, Julie Boberg, Camilla Taxvig, Mikael Pedersen, Henrik Lauritz Frandsen, Sofie Christiansen, Terje Svingen

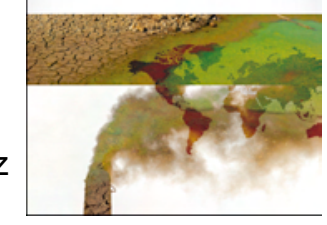

PII:

S0269-7491(19)33760-1

DOI:

https://doi.org/10.1016/j.envpol.2019.113309

Reference:

ENPO 113309

To appear in: Environmental Pollution

Received Date: 11 July 2019

Revised Date: 16 September 2019

Accepted Date: 24 September 2019

Please cite this article as: Kam Draskau, M., Boberg, J., Taxvig, C., Pedersen, M., Lauritz Frandsen, H., Christiansen, S., Svingen, T., In vitro and in vivo endocrine disrupting effects of the azole fungicides triticonazole and flusilazole, Environmental Pollution (2019), doi: https://doi.org/10.1016/ j.envpol.2019.113309.

This is a PDF file of an article that has undergone enhancements after acceptance, such as the addition of a cover page and metadata, and formatting for readability, but it is not yet the definitive version of record. This version will undergo additional copyediting, typesetting and review before it is published in its final form, but we are providing this version to give early visibility of the article. Please note that, during the production process, errors may be discovered which could affect the content, and all legal disclaimers that apply to the journal pertain.

(C) 2019 Published by Elsevier Ltd. 
1 In vitro and in vivo endocrine disrupting effects of the azole fungicides

2 triticonazole and flusilazole

3

4

5

7

8 9 10

a. Division of Diet, Disease Prevention and Toxicology, National Food Institute, Technical University of Denmark, Kemitorvet Building 202, Kongens Lyngby DK-2800, Denmark

b. Research Group for Analytical Food Chemistry, National Food Institute, Technical University of Denmark, Kemitorvet Building 202, Kongens Lyngby DK-2800, Denmark

c. Author for correspondence:

Tel: +4593518880

Email: tesv@food.dtu.dk

Running Title: Triticonazole and flusilazole elicit endocrine disrupting effects

Key words: conazoles, fungicides, endocrine disruptors, anogenital distance, anti-androgen, steroidogenesis 


\section{.} 45 6 48

\section{ABSTRACT}

Azoles are effective antifungal agents used in both medicine and agriculture. They typically work by inhibiting cytochrome P450 enzymes, primarily CYP51 of the ergosterol biosynthesis pathway, thus damaging the fungal cell membrane. However, apart from their desired antifungal properties, several azoles also exhibit endocrine disrupting properties in mammals, both in vitro and in vivo. Here, we have tested two currently used agricultural azole fungicides, triticonazole and flusilazole, for their in vitro anti-androgenic activity and potential effects on reproductive parameters. Both fungicides showed strong androgen receptor (AR) antagonism and disruption of steroid biosynthesis in vitro. Following gestational exposure to flusilazole (15 or $45 \mathrm{mg} / \mathrm{kg}$ bw/day) or triticonazole (150 or $450 \mathrm{mg} / \mathrm{kg}$ bw/day) in time-mated Sprague Dawley rats, triticonazole induced shorter male anogenital distance (AGD). Flusilazole exposure did not affect the AGD, but altered fetal male blood hormone profile, with increased androstenedione and decreased estrone levels. Flusilazole and triticonazole have dissimilar effects on reproductive parameters in vivo, but both show endocrine disrupting activities.

\section{7} 49 0 


\section{INTRODUCTION}

Prenatal and early postnatal development is considered particularly vulnerable periods for endocrine disruption, because this is when reproductive organs and neural systems are developing largely under the control of hormone signaling. Exposure to endocrine disrupting chemicals (EDCs) during fetal life is thus of great concern as it can perturb normal development and cause disease later in life. Potential EDCs comprise a plethora of compounds from diverse chemical classes, including phthalates, parabens, bisphenols, and azole fungicides.

Azoles are widely used as anti-fungal agents for crop protection. Their residues are frequently found in agricultural food products (EFSA, 2017; Petersen, 2017) and wastewater (Kahle et al., 2008). Azoles are also used in medicine for treating a range of human fungal infections including vaginal mycoses in pregnant women, which can result in high exposure concentrations. The broad use of azole compounds stems from their ability to inhibit the fungal enzyme Sterol $14 \alpha-$ demethylase (CYP51), causing a disruption of fungal membrane integrity (Zarn et al., 2003). However, several azoles also target mammalian CYP51 (Lamb et al., 1999) and other members of the CYP450 family (Zhang et al., 2002), including enzymes catalyzing crucial steps in steroidogenesis such as CYP19 (aromatase) (Ian Mason et al., 1985; Vinggaard et al., 2000), which converts androgens to estrogens. Furthermore, several azoles can affect hormone receptors such as the androgen receptor (AR) (Kjærstad et al., 2010; Roelofs et al., 2014). Azole fungicides can thus have off-target effects in mammals and perturb, for instance, reproductive development, a process that is dependent on sex hormone synthesis and signaling.

In humans, maternal use of oral azole anti-mycotic drugs during pregnancy has been associated with anti-androgenic effects such as shorter anogenital distance (AGD) in male offspring (Mogensen et al., 2017). This is supported by several animal studies where, for instance in rodents, 
prochloraz, tebuconazole and ketoconazole can induce feminization of male offspring, with effects such as increased nipple retention and shorter AGD (Hass et al., 2012; Laier et al., 2006; Taxvig et al., 2008, 2007; Vinggaard et al., 2005). Two other azoles, epoxiconazole and propiconazole, have been shown to hyper-masculinize male rat offspring (Goetz et al., 2007; Hass et al., 2012), which displayed longer AGD at some doses, which contradicts an anti-androgenic mode of action only. In fact, prochloraz, tebuconazole and epoxiconazole are azoles that also disrupt female reproductive development and cause masculinization effects (Hass et al., 2012; Laier et al., 2006; MelchingKollmuss et al., 2017; Taxvig et al., 2007), suggesting an androgenic mode of action. Together, these studies paint a more complex picture of adverse outcomes following exposure to commonly used azole fungicides, raising concerns about human exposure to these compounds.

We have tested two widely used azole pesticides, triticonazole and flusilazole, in an in vivo rat developmental toxicity study, as well as by endocrine relevant in vitro assays; the overall aim being to test whether these two azoles harbor endocrine disrupting properties. Triticonazole and flusilazole were chosen because they are current use fungicides, but also because they have shown differing activities in a zebrafish embryo model. Triticonazole was seen to primarily affect steroid biosynthesis, whereas flusilazole predominantly affected retinoic acid signaling as assessed by altered gene expression profiles (Hermsen et al., 2012). We report the adverse effects of triticonazole and flusilazole on male reproductive development in rats and present, to our knowledge, the first rodent in vivo toxicity study on triticonazole specifically targeting hormonesensitive endpoints, which can be used for future risk assessment or classification of this azole.

4

5 MATERIALS AND METHODS 
In this study we used flusilazole ( $\geq 95 \%$ pure, CAS No. 85509-19-9) from BOC Sciences (batch no. B18LN07171, New York, USA) and triticonazole (>95\% pure, CAS No. 131983-72-7) from Abcam (\#ab143728, lot no. GR3232419-3(N/A), Cambridge, UK). LC-MS grade acetonitrile, methanol, formic acid, ethyl acetate and 25\% ammonium hydroxide were from Sigma Aldrich (Schneldorf, Germany). Isolute bulk C-18 sorbent was obtained from Biotage, Sweden, the sorbent was washed with acetonitrile and ethyl acetate and dried prior to use. Water was purified on a Milli Q system (Millipore Corporation, US).

AR-EcoScreen ${ }^{T M}$ assay

The stably transfected AR-EcoScreen ${ }^{\mathrm{TM}}$ cell line (\#JCRB1328, Japanese Collection of Research Bioresources Cell Bank) was used to test human AR (hAR) agonistic and antagonistic effects of flusilazole and triticonazole largely as described by the OECD test guideline no. 458 (OECD, 2016). Briefly, cells were cultured in DMEM/F-12 medium supplemented with $5 \%$ fetal bovine serum, $1 \%$ Penicillin-Streptomycin, $200 \mu \mathrm{g} / \mathrm{mL}$ Zeocin, and $100 \mu \mathrm{g} / \mathrm{mL}$ Hygromycin (all purchased from Thermo Fisher Scientific). We used cells from passage 3-6, with cultures maintained at $37^{\circ} \mathrm{C}$ with a humidified atmosphere of $5 \% \mathrm{CO}_{2}$ and $95 \%$ air.

The day before exposure, cells were seeded in DMEM/F-12 supplemented with $1 \%$ PenicillinStreptomycin and 5\% dextran-coated charcoal-treated fetal bovine serum (Sigma-Aldrich ${ }^{\circledR}$ ) at a density of 90,000 cells/mL using $100 \mu \mathrm{L}$ cell solution/well in white 96-well plates (Perkin Elmer). Cells were exposed for $24 \mathrm{~h}$ in 2-fold serial dilutions with concentrations between $0.2-50 \mu \mathrm{M}$. For controls, the AR agonist R1881 (Perkin Elmer) was used in 2-fold serial dilutions from 0.008-1 nM and the AR antagonist hydroxyflutamide (OHF, Toronto Research Chemicals) was used in 3-fold serial dilutions from 4-9000 nM. When testing for AR antagonism, $0.1 \mathrm{nM} \mathrm{R} 1881$ was added to all 
wells, and for assessment of non-AR-mediated luminescence signals from triticonazole exposure, 1 $\mu \mathrm{M}$ OHF was added to all wells, and tested in 2-fold serial dilutions in concentrations from 1.6-50 $\mu \mathrm{M}$. DMSO was used as vehicle for test compounds and control compounds, with DMSO concentration kept constant $(0.1 \%)$ in all wells. Luciferase activity was measured on a Lumistar Galaxy luminometer (BMG LABTECH, Offenburg, Germany) using the Dual-GloLuciferase Reagent. Cytotoxicity was assessed by measuring Renilla luminescence using the Dual-Glo stop and Glo reagent (Promega, WI, USA). Experiments were performed in triplicate reactions and repeated thrice, except for non-AR-mediated luminescence signal testing which was repeated twice.

\section{H295R steroidogenesis assay}

The human adrenocortical carcinoma cell line H295R (CRL-2128 ${ }^{\mathrm{TM}}$, ATCC®, Virginia, USA) was used for testing effects on steroidogenesis as previously described (Rosenmai et al., 2013). We used cells from passage 4-6, cultured in DMEM/F-12-medium with L-glutamine and HEPES without phenol red (Invitrogen ${ }^{\mathrm{TM}}$, Life Technologies ${ }^{\mathrm{TM}}$, CA, USA), supplemented with $1 \%$ Corning® $\mathrm{ITS}^{\mathrm{TM}}+$ Premix Universal Culture Supplement (Corning, MA, USA, \#354352) and 2.5\% Corning® NuSerum $^{\mathrm{TM}}$ Culture Supplement (Corning, MA, USA, \#355100) at $37^{\circ} \mathrm{C}$ in a $5 \% \mathrm{CO}_{2}$ atmosphere.

The day before exposure, cells were seeded 300,000 per well in clear 24-well plates (VWRCorning®, NY, USA). Cells were exposed for $48 \mathrm{~h}$ to controls (Forskolin: $1 \mu \mathrm{M}, 10 \mu \mathrm{M}$ (SigmaAldrich) and Prochloraz: $0.3 \mu \mathrm{M}, 3 \mu \mathrm{M}$ (VWR-Bie \& Berntsen, Denmark) or test compounds (triticonazole and flusilazole in 2-fold serial dilutions with concentrations between $0.8-50 \mu \mathrm{M}$ ). Vehicle (DMSO) concentration was kept constant in all wells (0.1\%). After the incubation period, cytotoxicity was assessed by visual inspection and the medium transferred to new 24-well plates and stored at $-80^{\circ} \mathrm{C}$. Assay sensitivity was confirmed by measuring testosterone and estradiol in 
controls with Cayman ELISA kits (\#582701 and \#582251, Cayman Chemical, MI, USA) according to manufacturer's instructions and OECD test guideline no. 456 (OECD, 2011). All experiments were performed in triplicate reactions and repeated thrice.

\section{Hormone analysis in cell medium by HPLC-MS/MS}

Medium from the H295R steroidogenesis assay was collected and analyzed for steroid hormone levels. Before LC-MS/MS analysis, deuterated internal standards were added to the cell extracts and samples centrifuged at $15,000 \mathrm{~g}$ for $10 \mathrm{~min}$. Steroid hormones were separated, detected, and quantified using on-line-SPE LC-MS/MS, using an Oasis HLB column $(2.1 \times 20 \mathrm{~mm}, 15 \mu \mathrm{m})$. For $17 \beta$-estradiol and estrone analysis, a Kinetex $C_{18}$ column $(2.1 \times 100 \mathrm{~mm}, 2.6 \mu \mathrm{m})$ was used with an injection volume of $100 \mu 1$, measuring in ESI- mode using methanol, and $1 \mathrm{mM}$ ammonia in water as the mobile phases (gradient flow rate was $0.4 \mathrm{ml} / \mathrm{min}$ ). For the other hormones, an Ascentis Express $\mathrm{C}_{8}$ column $(2.1 \times 100 \mathrm{~mm}, 2.7 \mu \mathrm{m})$ was used with an injection volume of $100 \mu$, measuring in ESI-/ESI+ mode with acetonitrile and $0.1 \%$ formic acid in water as the mobile phases (gradient flow rate was $0.25 \mathrm{ml} / \mathrm{min})$.

We included 15 hormones in the assay, of which 11 were detected (underlined): aldosterone, androstenedione, corticosterone, cortisol, dehydroepiandrosterone (DHEA), 11-deoxycortisol, dihydrotestosterone (DHT), epitestosterone, 18-hydroxycortisol, 17 1 -hydroxyprogesterone, progesterone, pregnelonone, testosterone, estrone, and $\underline{17 \beta \text {-estradiol. }}$

The limit of quantification (LOQ) was $1.0 \mathrm{ng} / \mathrm{ml}$ for pregnelonone; 0.25 for deoxycortisol: 0.1 $\mathrm{ng} / \mathrm{ml}$ for corticosterone, DHEA, and DHT; $0.05 \mathrm{ng} / \mathrm{ml}$ for epi-testosterone and hydroxyprogesterone; $0.03 \mathrm{ng} / \mathrm{ml}$ for aldosterone; $0.02 \mathrm{ng} / \mathrm{ml}$ for corticosterone, estradiol, testosterone and androstenedione; $0.01 \mathrm{ng} / \mathrm{ml}$ for hydroxycortisol, progesterone, and estrone. For 
quantification, external calibration standards were run before and after the samples at levels of 0.05 , $0.1,0.2,0.5,1.0,2.0,10.0$ and $20 \mathrm{ng} / \mathrm{ml}$, with $4.0 \mathrm{ng} / \mathrm{ml}$ internal standards: (testosterone-d2, methyltestosterone-d3, progesterone-c2 and estradiol-d3 from EURL Wageningen and cortisol-d4 and deoxycortisol-d8 from LGC Standards). For testosterone, cortisol, deoxycortisol, estradiol and progesterone dedicated internal standard was used. Furthermore, cortisol-d4 was used for aldosterone, and hydroxyprogesterone; deoxycortisol-d8 was used for cortocosterone; progesteronec2 was used for pregnelonone and estradiol-d3 was used for estrone. However, some measured values in the groups with high azole-exposures were below the LOQ or the limit of detection. Values below the detection limit were set as zero. The limit of detection and LOQ were estimated as the concentrations corresponding to three and ten times signal-to-noise, respectively. The mass spectrometer was an EVOQ Elite Triple Quadropole Instrument from Bruker (Bremen, Germany) and the UPLC system was an Ultimate 3000 system with a DGP-3600RS dual-gradient pump. Data handling was done using the software MS Workstation v. 8.2.1.

\section{Animal Study}

Animal experiments had ethical approval from the Danish Animal Experiments Inspectorate (license number 2015-15-0201-00553). All methods were performed in accordance with relevant guidelines and regulations. Forty 10 weeks old, time-mated Sprague-Dawley specific pathogen free rats (Charles River, Germany, via SCANBUR, Karlslunde) were delivered to the Technical University of Denmark animal facilities at gestational day (GD) 3 (with the day following overnight mating denoted GD1). On GD4, dams were weighed and assigned to 5 groups of 4 animals each with similar body weight (bw) distributions. Animals were housed in pairs until GD17, thereafter individually under standard conditions in High Temperature polysulfone (H-TempTM) cages 
189 (Tecniplast, Italy) with wood chip bedding, nesting material and a wooden shelter (Tapvei, 190 Denmark). Animals were kept in a controlled environment with $12 \mathrm{~h}$ light/dark cycles, $55 \pm 5 \%$ 191 humidity, $22 \pm 1{ }^{\circ} \mathrm{C}$ temperature, and 10 air changes per hour. Animals were fed a standard soy and 192 alfalfa-free diet based on Altromin 1314 (Altromin GmbH, Germany). Tap water in Bisphenol A193 free bottles (Polysulfone $700 \mathrm{ml}$, 84-ACBT0702SU Tecniplast, Italy) was provided ad libitum.

194 An acclimatization period of 4 days was allowed before starting exposure on GD7. The rats were 195 weighed and gavaged each morning with vehicle (corn oil, Sigma-Aldrich, \#C867-2.5L, Denmark), 196 flusilazole (15 or $45 \mathrm{mg} / \mathrm{kg}$ bw/day) or triticonazole (150 or $450 \mathrm{mg} / \mathrm{kg}$ bw/day) until GD21. The 197 dams were given a dosing volume of $2 \mathrm{ml} / \mathrm{kg} \mathrm{bw}$.

Dams were exposed $1 \mathrm{hr} \pm 15 \mathrm{~min}$ before decapitation under $\mathrm{CO}_{2} / \mathrm{O}_{2}$-anesthesia. Uteri were collected, weighed, and the number of live fetuses, location in uterus, resorptions, and implantations were registered. Body weight and any anomalies of the fetuses were recorded. Maternal and fetal trunk blood was collected and transferred to heparin-coated vials. Fetal blood was pooled for each sex within each litter. Blood samples were kept on ice before centrifugation at $4000 \mathrm{rpm}$ at $4{ }^{\circ} \mathrm{C}$ for 10 min after which the plasma was transferred to new tubes and stored at $-80{ }^{\circ} \mathrm{C}$.

Amniotic fluid was collected from all fetuses using disposable glass Pasteur pipettes, pooled within each litter, snap frozen in liquid nitrogen and subsequently stored at $-80{ }^{\circ} \mathrm{C}$. Maternal livers were weighed, and three standard pieces were cut and fixed in $10 \%$ formalin. Anogenital distance 209 (AGD), the distance between the genital papilla and the anus, was measured using a stereomicroscope with a micrometer eyepiece by an experienced technician blinded with respect to 
treatment groups. Fetal testes were dissected under a stereomicroscope and immediately placed in Bouin's fixative.

\section{Triazole concentrations in amniotic fluid and fetal plasma measured by LC-QTOF}

Flusilazole and triticonazole concentrations in fetal plasma and amniotic fluid were measured by

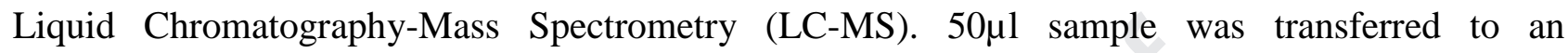
Eppendorf vial containing $150 \mu \mathrm{l}$ acetonitrile. Approximately $50 \mathrm{mg}$ Isolute $\mathrm{C} 18$ sorbent was added and the vial vortexed briefly, incubated at $4^{\circ} \mathrm{C}$ for $30 \mathrm{~min}$, and centrifuged at $10,000 \times \mathrm{g}$ for $10 \mathrm{~min}$ at $4{ }^{\circ} \mathrm{C}$ (Ole Dich Instrument makers, Denmark).Prior to analysis, $20 \mu 1$ of the supernatant was transferred to an HPLC vial and mixed with $80 \mu 175 \%$ acetonitrile.

LC was performed on a Dionex Ultimate 3000 RS (Thermo Scientific, CA) with a Poroshell SB C-8 (100x2.1 mm, $2.7 \mu \mathrm{m}$ particle size) column held at $40^{\circ} \mathrm{C}$ (Agilent technologies, Walbron, Germany). The solvent system consisted of A: $2.5 \mathrm{mM}$ ammonium hydroxide $+0.1 \%$ formic acid in water and B: acetonitrile. Solvent programming were: $0 \% \mathrm{~B}$ from 0 to 1 min followed by a linear gradient to $5 \%$ B to $3 \mathrm{~min}$ and a linear gradient to $98 \%$ B to $10 \mathrm{~min}$, isocratic $98 \%$ B from 10 to 12 min followed by reversal to initial conditions to $12.1 \mathrm{~min}$ and re-equilibration of the column to 15 min. The flow rate was $0.3 \mathrm{ml} / \mathrm{min}$ from 0 to $1 \mathrm{~min}$ followed by a linear gradient to $0.4 \mathrm{ml} / \mathrm{min}$ to $10 \mathrm{~min}$, which was held to $12 \mathrm{~min}$ followed by reversal to initial conditions.

The LC system was connected to a Bruker Daltonics, maXis qTOF MS equipped with an electrospray ion source operated in positive ion mode (Bruker Daltonics, Bremen, Germany). The ion source settings were: nebulizer pressure 2 bars, drying gas flow $81 / \mathrm{min}$, dry gas temperature $200{ }^{\circ} \mathrm{C}$, capillary voltage $2500 \mathrm{~V}$. The scan range was from 80 to $700 \mathrm{~m} / \mathrm{z}$ with an acquisition rate of $2 \mathrm{~Hz}$. Sodium formate dissolved in 50\% 2-propanol was introduced in the ion source in a $0.2-0.4$ 
234 min time segment and used for internal calibration of the data files. 235 Hexakisperflouroetoxyphophazene was used as lock mass calibrant to compensate for drift in the 236 mass axis during analysis.

237 Matrix matched standard samples were prepared in blank plasma at 4-5 different levels in the 238 concentration range of: flusilazole 0.6 to $74.5 \mathrm{ng} / \mathrm{ml}$, triticonazole 0.73 to $910 \mathrm{ng} / \mathrm{ml}$. Standards and 239 blanks were analyzed in the beginning of a sequence and after each set of 20 samples. Data files 240 were processed using QuantAnalysis (Bruker Daltonics, Bremen, Germany). Extracted ion 241 chromatograms of $\mathrm{m} / \mathrm{z} 316.1076 \pm 0.003 \mathrm{Da}$ (flusilazole) and $\mathrm{m} / \mathrm{z} 318.1368 \pm 0.003 \mathrm{Da}$ 242 (triticonazole) were constructed and integrated. Plasma concentrations were calculated based on 243 linear calibration curves constructed using 1/x weighing.

Plasma samples were analyzed for steroid hormone levels by LC-MS/MS as previously described Plasma samples were thawed on ice and $100 \mu 1$ added to an Eppendorf vial containing $300 \mu 1$ icecold, $2 \%$ formic acid in acetonitrile with $3.33 \mathrm{ng} / \mathrm{ml}$ internal standard (deoxycortisol-d8 and cortisol-d4 from Ceriliant, methyltestosterone-d3, beta-testosterone-d2, beta-estradiol-d3 and progesterone-c 2 from Rikilt), then vortexed for $5 \mathrm{~s}$. The vial was then placed at $-20^{\circ} \mathrm{C}$ for 20 min and centrifuged at $10,000 \mathrm{~g}$ for $7 \mathrm{~min}$ at $4^{\circ} \mathrm{C}$. The supernatant was subsequently transferred to a tube containing approximately $50 \mathrm{mg}$ Supel $^{\mathrm{TM}}$ QuE Z-Sep powder (Supelco, Bellefonte, PA, USA, \#55418-U) and briefly vortexed, then shaken for $60 \mathrm{~s}$, before centrifugation for $3 \mathrm{~min}$ at $3500 \mathrm{~g}$. 


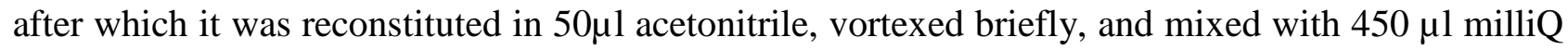
water.

Steroid hormones were separated, detected, and quantified using on-line-SPE LC-MS/MS exactly as described above for analysis of the H295R steroidogenesis assay. Out of 14 hormones assayed for, we detected 6 (underlined): testosterone, epitestosterone, androstenedione, dehydroepiandrosterone (DHEA), dihydrotestosterone (DHT), corticosterone, cortisol, hydroxycortisol, deoxycortisol, pregnenolone, progesterone, 17 $\alpha$-OH-progesterone, estradiol, and estrone.

Limit of quantification (LOQ) was estimated as the concentration corresponding to 10 times the signal to noise ratio of plasma samples spiked with analyte. LOQs were estimated to be $0.1 \mathrm{ng} / \mathrm{ml}$ for androstenedione, progesterone, testosterone and estrone, $0.3 \mathrm{ng} / \mathrm{ml}$ for corticosterone, and 2.0 $\mathrm{ng} / \mathrm{ml}$ for pregnenolone. For quantification, external calibration standards were run before and after the samples at concentrations of $0.02,0.05,0.1,0.2,0.5,1.0,2.0$, and $5.0 \mathrm{ng} / \mathrm{ml}$, with $2.0 \mathrm{ng} / \mathrm{ml}$ internal standard. Blank plasma samples were spiked with analyte at three concentration levels: 0.0 (blank sample), 0.5 , and $2.0 \mathrm{ng} / \mathrm{ml}$ and run for quality control. The mass spectrometer was an EVOQ Elite Triple Quadropole Instrument from Bruker (Bremen, Germany) and the UPLC system was an Ultimate 3000 system with a DGP-3600RS dual-gradient pump. Data handling was performed in MS Workstation v. 8.2.1 software.

\section{Histopathology}

One Bouin's fixed testis from each litter in all dose groups (7-8 testes per dose group, 39 testes in total), was randomly selected for histopathological examination. Two sections per testis were stained with Meyer's hematoxylin and eosin (H\&E) and evaluated (dose group blinded to observer) 
by light microscopy for the presence of multinucleated gonocytes, small or large Leydig cell clusters, edemas, and testis cord dysmorphology. Maternal livers (one section per liver) were stained with H\&E and evaluated (dose group blinded to observer) by light microscopy for the presence of vacuolization, infiltrations and hypertrophy.

\section{Statistical analyses}

Data from the in vitro assays, analysis of in vivo internal triazole concentrations, analysis of hormone levels in fetal plasma, maternal parameters and litter data were assessed for normal distribution by residual statistics. Data not normally distributed were log-transformed and assessed again to confirm normality. Normally distributed data were analyzed using one-way ANOVA followed by Dunnett's multiple comparison test using GraphPad Prism 8 (GraphPad Software, San Diego, CA, USA). Homogeneity of variance was confirmed by residual statistics and applying Bartlett's test. Non-normally distributed data was analyzed by Kruskal-Wallis followed by Dunn's multiple comparison test using GraphPad Prism 8 (GraphPad Software, San Diego, CA, USA).

In vivo data on fetal body weight, AGD and AGD index (AGDi, AGD/cube root of bw) at GD21, were analyzed using one-way ANOVA followed by Dunnett's post hoc test using SAS ${ }^{\circledR}$ (SAS Enterprise Guide 6.1, SAS Institute, USA). Statistical analyses of AGD and AGDi were adjusted using litter as an independent, random and nested factor and analyzed using body weight as a covariate. Fetal body weights were analyzed using the number of offspring per litter as covariate. For all analyses, the litter was the statistical unit.

\section{RESULTS}


301

302 303 304 305 306

\section{Flusilazole and triticonazole antagonizes AR in vitro}

In the AR-EcoScreen ${ }^{\mathrm{TM}}$ assay, both flusilazole and triticonazole were strong hAR antagonists. Flusilazole had a lowest observed effect concentration (LOEC) of $0.8 \mu \mathrm{M}$ and an $\mathrm{IC}_{50}$ of $2.8( \pm 0.1)$ $\mu \mathrm{M}$, whereas triticonazole had a LOEC of $0.2 \mu \mathrm{M}$ and an $\mathrm{IC}_{50}$ of $0.3( \pm 0.01) \mu \mathrm{M}$ (Fig. 1A). In addition, triticonazole showed hAR agonistic activity at the highest doses; 25 and $50 \mu \mathrm{M}$, whereas flusilazole did not. However, addition of $1 \mu \mathrm{M}$ of the AR antagonist OHF did not diminish the triticonazole-induced luciferase response at 25 and $50 \mu \mathrm{M}$ (Fig. 1B). Flusilazole induced cytotoxicity at the two highest doses of 25 and $50 \mu \mathrm{M}$ (Fig. 1C), thus these data points were excluded from statistical analyses. No cytotoxicity was observed for triticonazole at any of the tested doses (Fig. 1D).

\section{Triticonazole and flusilazole disrupts steroidogenesis in vitro}

Flusilazole affected all steroid hormones in the H295R Steroidogenesis assay (Fig. 2A). Pregnenolone, 17 $\alpha$-hydroxyprogesterone, corticosterone, cortisol, 11-deoxycortisol, DHEA, androstenedione, testosterone, estrone, and $17 \beta$-estradiol levels were decreased with LOECs of down to $0.78 \mu \mathrm{M}$. Progesterone levels were strongly increased with a LOEC of $3.13 \mu \mathrm{M}$. Triticonazole affected most steroid hormones, except DHEA, but showed a different pattern of effects than flusilazole (Fig. 2B): pregnenolone, corticosterone, cortisol, deoxycortisol, and androstenedione were all decreased, whereas estrone, $17 \beta$-estradiol, and testosterone were increased at low doses, but decreased at $50 \mu \mathrm{M}$. Progesterone was slightly decreased between 0.78 and $6.25 \mu \mathrm{M}$, whereas $17 \alpha$-hydroxyprogesterone was increased with a LOEC of $12.5 \mu \mathrm{M}$.

\section{Flusilazole and triticonazole were present in both amniotic fluid and fetal plasma}


Flusilazole and triticonazole were measured in amniotic fluid and plasma from GD21 fetuses by LC-MS. As seen in Table 1 and Fig. 3, concentration of flusilazole and triticonazole increased in a dose-dependent manner relative to exposure levels, both in plasma and amniotic fluid. For flusilazole, the concentration in plasma was around 3.5-fold higher than in amniotic fluid, and there was a 3-fold increase in internal dose from the 15 to the $45 \mathrm{mg} / \mathrm{kg}$ dose groups. For triticonazole, the concentration in plasma was 3- to 4-fold higher than in amniotic fluid, and there was around a 2fold increase in internal doses from 150 to the $450 \mathrm{mg} / \mathrm{kg}$ bw dose groups.

\section{Administered doses of triticonazole and flusilazole induced only mild toxicity at highest doses}

We observed no external signs of maternal toxicity, no significant differences in maternal bw gain (from GD7-21) or adjusted maternal bw (bw after subtracting uterus weight), nor irregular litter sizes between groups at GD21 (Table 2). However, both flusilazole and triticonazole induced an increase in number of late resorptions in the highest dose groups, albeit not statistically significant (Table 2). One occurrence of a very late resorption (around GD18) was also observed in the highest flusilazole exposure group. In addition, we observed mild hepatocellular centrilobular hypertrophy consistent with an increased induction of hepatic enzymes in the dams from the high dose groups for both fungicides, along with incidences of focal necrosis in the flusilazole high dose group (data not shown).

\section{Male fetuses exposed to triticonazole in utero display shorter anogenital distance}

AGD was shorter in male fetuses at GD21 after in utero exposure to triticonazole, also when accounting for bodyweight (AGDi, AGD/cube root of bw): 10\% shorter AGD and 8\% shorter AGDi in the $450 \mathrm{mg} / \mathrm{kg}$ bw group, and $4 \%$ smaller AGDi in the $150 \mathrm{mg} / \mathrm{kg}$ bw group. Female AGD was not significantly affected by triticonazole exposure. For flusilazole, neither male nor female 
offspring displayed significant changes to AGD in any of the exposure groups, 15 or $45 \mathrm{mg} / \mathrm{kg}$ bw (Table 2, Fig. 4).

Flusilazole affects androstenedione and estrone levels in fetal male plasma

Androstenedione levels were significantly elevated in male fetuses exposed to either 15 or $45 \mathrm{mg} / \mathrm{kg}$ bw flusilazole. Estrone levels were lower in the $45 \mathrm{mg}$ flusilazole/kg bw group. We observed no changes for pregnenolone, progesterone, corticosterone or testosterone levels in fetal male plasma. Triticonazole had no significant effect on the measured hormone levels in male fetuses (Fig. 6).

\section{Flusilazole or triticonazole exposure did not affect testis histology}

Histopathological examination of GD21 testes did not reveal any histological changes in response to azole exposure.

\section{DISCUSSION}

We have examined potential anti-androgenic and prenatal reproductive effects in rats caused by fetal exposure to the azole fungicides triticonazole and flusilazole. Many azoles can disrupt reproductive development in rodents, likely through endocrine disrupting mechanisms of action. Furthermore, rodent studies have revealed a complex pattern of effects, for instance with shorter AGD and increased nipple retention in males (Hass et al., 2012; Laier et al., 2006; Taxvig et al., 2008, 2007; Vinggaard et al., 2005), but also longer AGD in both males and females (Goetz et al., 2007; Hass et al., 2012; Laier et al., 2006; Melching-Kollmuss et al., 2017; Taxvig et al., 2007). It 
therefore seems difficult to predict in vivo effects of the various azole compounds, which also proved to be the case for triticonazole and flusilazole.

Since many azoles have shown AR antagonistic effects in vitro, we tested both triticonazole and flusilazole using the human AR-EcoScreen ${ }^{\mathrm{TM}}$ assay (Kjærstad et al., 2010). Both compounds proved to be strong hAR antagonists, with triticonazole being the most potent with a 10 -fold lower $\mathrm{IC}_{50}$ value of $0.3 \mu \mathrm{M}$, compared to $2.8 \mu \mathrm{M}$ for flusilazole. These values are smaller than reported in a human breast cancer cell line, where $\mathrm{IC}_{50}$ were $11.9 \mu \mathrm{M}$ for flusilazole and $10.7 \mu \mathrm{M}$ for triticonazole (Roelofs et al., 2014), suggesting less hAR antagonistic potency than was seen in our assay. This discrepancy, however, could be caused by simple assay and cell type variations. Regardless, flusilazole and triticonazole can both interfere with the hAR, which can have detrimental effects for reproductive development and function.

Apart from showing anti-androgenic potential, triticonazole also showed agonistic activity at high concentrations (from $25-50 \mu \mathrm{M}$ ) without signs of increased cell proliferation. This could indicate that triticonazole is a selective hAR modulator, but could also be due to a variety of other reasons. Firstly, triticonazole could mediate a stabilization of the luciferase reporter, as it has previously been reported for other chemicals tested in this assay (OECD, 2016). Secondly, the AREcoScreen ${ }^{\mathrm{TM}}$ cell line expresses the glucocorticoid receptor, which has affinity for the androgenresponsive element, and could thus increase luminescence upon activation and lead to false positive results (OECD, 2016; Satoh et al., 2005). However, addition of the AR antagonist OHF indicated that the observed rise in luciferase reporter activation at high triticonazole concentrations was not AR-mediated.

Azole fungicides are frequently reported to interfere with steroidogenesis. This includes in vitro down-regulation of testosterone and estradiol (Kjærstad et al., 2010; Taxvig et al., 2013), and up- or 
391

392

393

394

395

396

397

398

399

400

401

402

403

404

405

406

407

408

409

410

411

412

413

414

down-regulation of progesterone (Kjærstad et al., 2010; Taxvig et al., 2013). We thus analyzed the effects of flusilazole and triticonazole on steroid biosynthesis using the H295R steroidogenesis assay. Both triazoles strongly disrupted steroid hormone synthesis. Flusilazole downregulated pregnenolone, corticosteroid, androgen and estrogen synthesis. Estrone and estradiol levels were remarkably low already at the lowest flusilazole concentration tested, indicating a potent inhibitory effect of flusilazole on aromatase (CYP19), which converts androstenedione and testosterone to estrone and estradiol. This fits well with previous studies where inhibition of aromatase, demonstrated in in vitro assays, has been suggested to underlie steroidogenic disturbances in response to azole exposure (Vinggaard et al., 2000). However, these effects on the steroidogenic pathway could also indicate that flusilazole inhibits 17 $\alpha$-hydroxylase (CYP17A1), 17,20-lyase (CYP17A1), 21-hydroxylase (CYP21A2), 11ß-hydroxylase (CYP11B1), cholesterol side-chain

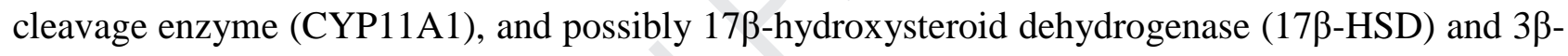
HSD. Notably, with regard to the more than 5-fold increase in progesterone levels, we speculate a strong inhibitory effect on $17 \alpha$-hydroxylase activity. Overall, flusilazole seems to affect sexhormone synthesis, but also corticosteroid and progestagen biosynthesis.

Triticonazole seemed to have strongest effect on corticosteroid and progestagen synthesis, inhibiting pregnenolone synthesis and all corticosteroids measured, potentially via 21-hydroxylase, 11ß-hydroxylase, and cholesterol side-chain cleavage enzyme. 17-hydroxyprogesterone levels were elevated, indicating stimulatory effects on 17 $\alpha$-hydroxylase or inhibitory effects on 21-hydroxylase or 17,20-lyase. Effects on androgens and estrogens, on the other hand, were differing between lower and higher triticonazole concentrations, with an increase of testosterone, estrone and estradiol levels but a decrease in these hormones at the highest concentration tested, $50 \mu \mathrm{M}$; a decrease that was also seen in androstenedione levels at the highest concentration. It cannot be excluded that these lower hormone levels at high azole exposure concentrations is a consequence of cellular 
415 cytotoxicity; however, it is worth noting that in the AR-EcoScreen ${ }^{\mathrm{TM}}$ assay, triticonazole had strong antagonistic effects on the hAR, but showed agonistic effects on the hAR at these same high concentrations.

Having shown clear anti-androgenic activity of both triticonazole and flusilazole in vitro, we tested their endocrine disrupting effects on pregnant rats. In utero exposure to triticonazole induced short fetal male AGD, whereas flusilazole exposure did not affect fetal AGD in either sex. A short male AGD is a sign of androgen insufficiency during the masculinization programming window (Welsh et al., 2008), and is used as a broad biomarker in reproductive toxicity studies screening for antiandrogenicity as it is associated with several male reproductive disorders (Schwartz et al., 2019a). Having displayed anti-androgenic effects both in vitro and in vivo, triticonazole thus emerges a clear anti-androgenic compound that is predicted to have detrimental effects on male reproductive development, depending on exposure context. Although it is highly unlikely that human fetuses will be exposed to such high doses, triticonazole adds to the overall burden of environmental chemicals with anti-androgenic potential. It is important to note that these endocrine disruptive effects were not shown in the toxicity studies used for the European approval of the fungicide, where it was concluded, that any signs of effects on hormonal balance were likely the consequence of general toxicity. This shows the importance of conducting in vitro screenings followed by targeted studies of hormone-sensitive endpoints (EFSA, 2005).

433 In contrast to triticonazole, flusilazole did not induce a shorter male AGD following in utero 434 exposure at the applied doses. Based on available toxicity data for flusilazole, however, a dose 435 higher than $45 \mathrm{mg} / \mathrm{kg}$ bw/day would likely cause maternal and fetal toxicity (WHO, 1996).

436 Triticonazole and flusilazole are examples of azole compounds that probably have different 437 mechanisms of action. In a zebrafish embryo model, triticonazole exposure was shown to primarily 
affect the expression of genes related to steroid biosynthesis, whereas flusilazole exposure seemed to have bigger effects on genes involved in retinoic acid signaling (Hermsen et al., 2012), an effect of flusilazole, which has also been observed in rat embryos (Dimopoulou et al., 2016). In support of dissimilar mechanistic profiles, we observed no changes to plasma steroid hormone levels in the triticonazole-exposed male fetuses at GD21, yet shorter male AGD. Flusilazole, on the other hand, caused significantly higher levels of androstenedione and lower levels of estrone in exposed fetuses, which could indicate inhibition of aromatase (CYP19) activity. This fits with results from the in vitro steroidogenesis assay, where flusilazole completely repressed estrone and estradiol levels. In contrast to the in vivo flusilazole-induced higher levels of androstenedione and no effects on the other hormones, flusilazole exposure resulted in lower levels of androstenedione as well as lower levels of the other androgens and corticosteroids analyzed in vitro. It is possible that feedback mechanisms are able to restore hormone levels to normal, despite inhibitory effects of flusilazole on several enzymes in the steroid biosynthesis, whereas the very strong inhibitory effect on aromatase results in the low estrone levels and consequently increased androstenedione levels.

Intriguingly, fetal flusilazole exposure did not result in altered AGD despite predicted strong antiandrogenic effects from the in vitro assays. It could be speculated that flusilazole induces opposing endocrine disruptive mechanisms of action, where an inhibitory effect on the androgen receptor is counteracted by an inhibitory effect on aromatase causing high fetal androgen levels. Notably, recent data suggests that estrogen signaling also plays a role in male reproductive development (Sathyanarayana et al., 2012; Schwartz et al., 2019b; Stewart et al., 2018) beyond its role in mouse penile development (Govers et al., 2019; Zheng et al., 2015). This warrants further studies on the possible consequences of flusilazole-induced lower estrogen levels in male fetuses.

We could detect both flusilazole and triticonazole in amniotic fluid and fetal plasma at GD21, confirming that both compounds can cross the placental barrier. Concentrations were generally 
lower in amniotic fluid than in plasma, indicating extensive metabolism of both flusilazole and triticonazole before excretion. The large standard errors in the high dose groups indicate that the azoles have been absorbed or metabolized to different degrees in each litter, likely caused by biological differences in pharmacokinetics.

The fetal plasma concentration of triticonazole was more than 17 -fold higher than the $\mathrm{IC}_{50}$ of 0.3 $\mu \mathrm{M}$ for hAR antagonism observed in vitro, whereas fetal plasma flusilazole levels were below the $\mathrm{IC}_{50}$ for hAR antagonism, but the high-dosed animals did show values more than 2 times above the LOEC of $0.8 \mu \mathrm{M}$. In addition, plasma concentrations of triticonazole were above LOEC for in vitro effects on corticosteroid, progestagen, testosterone, and estrogen biosynthesis in both dose groups, whereas flusilazole plasma concentrations only reached levels with in vitro effects for corticosteroid, testosterone and estrogen biosynthesis, but contrary to triticonazole did show effects on in vivo androstenedione and estrone levels.

The endocrine-disrupting effects, in rats, for the two azoles are seen at doses above no observed adverse effect levels (NOAELs) used to set acceptable daily intake (ADI) values, whereas human exposure from foods is far lower than these doses (EFSA, 2017; Jensen et al., 2019). However, several other EDCs, including, but not limited to, azole compounds, are known to affect the male reproductive system (Ribeiro et al., 2017; Rodprasert et al., 2019), and each of these compounds may contribute to a combined effect. The exact contribution of triticonazole and flusilazole to the human load of male reproductive toxicants would require further studies on toxicokinetics, species differences, and lowest effective concentrations in vivo. However, triticonazole, in particular, fits the pattern of an anti-androgenic compound that can affect male reproductive development. Flusilazole, on the other hand, seems to affect fetal development in a different manner than triticonazole at the applied doses. It would be of interest to further characterize how flusilazole affects reproductive tissues during development to improve chemical risk assessment. 


\section{ACKNOWLEDGMENTS}

488 We would like to thank our technical staff, Lillian Sztuk, Dorte Lykkegaard Korsbech, Birgitte 489 Møller Plesning, Mette Voigt Jessen, Stine Marie Stysiek, and Heidi Letting, for their valuable 490 contributions. We also thank our in-house animal facilities headed by Anne-Marie Ørngreen. In 491 addition, we thank Professor Henrik Elvang Jensen from Department of Veterinary and Animal 492 Sciences, Pathobiological Sciences at University of Copenhagen, for his assistance with liver 493 histopathology analysis.

\section{FUNDING}

495 This work was funded by the Danish Environmental Protection Agency as a project under the 496 Centre on Endocrine Disrupters (CEHOS). The funding body (Danish EPA) had no involvement in 497 study design; in the collection, analysis and interpretation of data; in the writing of the report; or in 498 the decision to submit the article for publication. 


\section{REFERENCES}

Dimopoulou, M., Verhoef, A., van Ravenzwaay, B., Rietjens, I.M.C.M., Piersma, A.H., 2016. Flusilazole induces spatio-temporal expression patterns of retinoic acid-, differentiation- and sterol biosynthesis-related genes in the rat Whole Embryo Culture. Reprod. Toxicol. 64, 7785. https://doi.org/10.1016/J.REPROTOX.2016.04.003

EFSA, 2017. The 2015 European Union report on pesticide residues in food. EFSA J. 15, e04791. https://doi.org/10.2903/j.efsa.2017.4791

EFSA, 2005. Conclusion regarding the peer review of the pesticide risk assessment of the active substance triticonazole. EFSA J. 3, 69. https://doi.org/10.2903/j.efsa.2005.33ar

Goetz, A.K., Ren, H., Schmid, J.E., Blystone, C.R., Thillainadarajah, I., Best, D.S., Nichols, H.P., Strader, L.F., Wolf, D.C., Narotsky, M.G., Rockett, J.C., Dix, D.J., 2007. Disruption of Testosterone Homeostasis as a Mode of Action for the Reproductive Toxicity of Triazole Fungicides in the Male Rat. Toxicol. Sci. 95, 227-239. https://doi.org/10.1093/toxsci/kfl124

Govers, L.C., Phillips, T.R., Mattiske, D.M., Rashoo, N., Black, J.R., Sinclair, A., Baskin, L.S., Risbridger, G.P., Pask, A.J., 2019. A critical role for estrogen signaling in penis development. FASEB J. fj.201802586RR. https://doi.org/10.1096/fj.201802586RR

Hadrup, N., Pedersen, M., Skov, K., Hansen, N.L., Berthelsen, L.O., Kongsbak, K., Boberg, J., Dybdahl, M., Hass, U., Frandsen, H., Vinggaard, A.M., 2016. Perfluorononanoic acid in combination with 14 chemicals exerts low-dose mixture effects in rats. Arch. Toxicol. 90, 661-675. https://doi.org/10.1007/s00204-015-1452-6

Hass, U., Boberg, J., Christiansen, S., Jacobsen, P.R., Vinggaard, A.M., Taxvig, C., Poulsen, M.E., Herrmann, S.S., Jensen, B.H., Petersen, A., Clemmensen, L.H., Axelstad, M., 2012. Adverse 
effects on sexual development in rat offspring after low dose exposure to a mixture of endocrine disrupting pesticides. Reprod. Toxicol. 34, 261-274. https://doi.org/10.1016/J.REPROTOX.2012.05.090

Hermsen, S.A.B., Pronk, T.E., van den Brandhof, E.-J., van der Ven, L.T.M., Piersma, A.H., 2012. Triazole-induced gene expression changes in the zebrafish embryo. Reprod. Toxicol. 34, 216224. https://doi.org/10.1016/j.reprotox.2012.05.093

Ian Mason, J., Murry, B.A., Olcott, M., Sheets, J.J., 1985. Imidazole antimycotics: Inhibitors of steroid aromatase. Biochem. Pharmacol. 34, 1087-1092. https://doi.org/10.1016/00062952(85)90613-6

Jensen, B.H., Petersen, A., Petersen, P.B., Poulsen, M.E., Nielsen, E., Christensen, T., Fagt, S., Trolle, E., Andersen, J.H., 2019. Pesticide Residues in Food on the Danish Market Results from the period Division for Risk Assessment and Nutrition.

Kahle, M., Buerge, I.J., Hauser, A., Müller, M.D., Poiger, T., 2008. Azole fungicides: occurrence and fate in wastewater and surface waters. Environ. Sci. Technol. 42, 7193-200. https://doi.org/https://doi.org/10.1021/es8009309

Kjærstad, M.B., Taxvig, C., Nellemann, C., Vinggaard, A.M., Andersen, H.R., 2010. Endocrine disrupting effects in vitro of conazole antifungals used as pesticides and pharmaceuticals. Reprod. Toxicol. 30, 573-582. https://doi.org/10.1016/J.REPROTOX.2010.07.009

Laier, P., Metzdorff, S.B., Borch, J., Hagen, M.L., Hass, U., Christiansen, S., Axelstad, M., Kledal, T., Dalgaard, M., McKinnell, C., Brokken, L.J.S., Vinggaard, A.M., 2006. Mechanisms of action underlying the antiandrogenic effects of the fungicide prochloraz. Toxicol. Appl. Pharmacol. 213, 160-71. https://doi.org/10.1016/j.taap.2005.10.013 
544 Lamb, D.C., Kelly, D.E., Waterman, M.R., Stromstedt, M., Rozman, D., Kelly, S.L., 1999. 545 Characteristics of the heterologously expressed human lanosterol $14 \alpha$-demethylase (other

Mogensen, D.M., Pihl, M.B., Skakkebæk, N.E., Andersen, H.R., Juul, A., Kyhl, H.B., Swan, S., Kristensen, D.M., Andersen, M.S., Lind, D.V., Jensen, T.K., 2017. Prenatal exposure to antifungal medication may change anogenital distance in male offspring: a preliminary study. Environ. Heal. 16, 68. https://doi.org/10.1186/s12940-017-0263-z

OECD, 2016. Test No. 458: Stably Transfected Human Androgen Receptor Transcriptional Activation Assay for Detection of Androgenic Agonist and Antagonist Activity of Chemicals, OECD Guide. ed, OECD Guidelines for the Testing of Chemicals, Section 4. OECD Publishing. https://doi.org/10.1787/9789264264366-en

OECD, 2011. Test No. 456: H295R Steroidogenesis Assay, OECD Guide. ed, OECD Guidelines for the Testing of Chemicals, Section 4. OECD Publishing. https://doi.org/10.1787/9789264122642-en

Petersen, A., 2017. Pesticide Residues in Food on the Danish Market Pesticide Residues in Food on the Danish Market. 
Ribeiro, E., Ladeira, C., Viegas, S., 2017. EDCs Mixtures: A Stealthy Hazard for Human Health? Toxics 5. https://doi.org/10.3390/toxics5010005

Rodprasert, W., Main, K.M., Toppari, J., Virtanen, H.E., 2019. Associations between male reproductive health and exposure to endocrine-disrupting chemicals. Curr. Opin. Endocr. Metab. Res. 7, 49-61. https://doi.org/10.1016/J.COEMR.2019.05.002

Roelofs, M.J.E., Temming, A.R., Piersma, A.H., van den Berg, M., van Duursen, M.B.M., 2014. Conazole fungicides inhibit Leydig cell testosterone secretion and androgen receptor activation in vitro. Toxicol. reports 1, 271-283. https://doi.org/10.1016/j.toxrep.2014.05.006

Rosenmai, A.K., Nielsen, F.K., Pedersen, M., Hadrup, N., Trier, X., Christensen, J.H., Vinggaard, A.M., 2013. Fluorochemicals used in food packaging inhibit male sex hormone synthesis. Toxicol. Appl. Pharmacol. 266, 132-142. https://doi.org/10.1016/J.TAAP.2012.10.022

Sathyanarayana, S., Swan, S.H., Farin, F.M., Wilkerson, H.-W., Bamshad, M., Grady, R., Zhou, C., Schwartz, S.M., 2012. A pilot study of the association between genetic polymorphisms involved in estrogen signaling and infant male genital phenotypes. Asian J. Androl. 14, 76672. https://doi.org/10.1038/aja.2012.27

Satoh, K., Nonaka, R., Ohyama, K., Nagai, F., 2005. Androgenic and Antiandrogenic Effects of Alkylphenols and Parabens Assessed Using the Reporter Gene Assay with Stably Transfected CHO-K1 Cells (AR-EcoScreen System). J. Heal. Sci. 51, 557-568. https://doi.org/10.1248/jhs.51.557

Schwartz, C.L., Christiansen, S., Vinggaard, A.M., Axelstad, M., Hass, U., Svingen, T., 2019a. Anogenital distance as a toxicological or clinical marker for fetal androgen action and risk for reproductive disorders. Arch. Toxicol. 93, 253-272. https://doi.org/10.1007/s00204-018-2350- 
Schwartz, C.L., Vinggaard, A.M., Christiansen, S., Darde, T.A., Chalmel, F., Svingen, T., 2019 b. Distinct Transcriptional Profiles of the Female, Male, and Finasteride-Induced Feminized Male Anogenital Region in Rat Fetuses. Toxicol. Sci. 169, 303-311. https://doi.org/10.1093/toxsci/kfz046

Stewart, M.K., Mattiske, D.M., Pask, A.J., 2018. In utero exposure to both high- and low-dose diethylstilbestrol disrupts mouse genital tubercle development $\dagger$. Biol. Reprod. 99, 1184-1193. https://doi.org/10.1093/biolre/ioy142

Taxvig, C., Hadrup, N., Boberg, J., Axelstad, M., Bossi, R., Bonefeld-Jørgensen, E.C., Vinggaard, A.M., 2013. In vitro - in vivo correlations for endocrine activity of a mixture of currently used pesticides. Toxicol. Appl. Pharmacol. 272, 757-766. https://doi.org/10.1016/J.TAAP.2013.07.028

Taxvig, C., Hass, U., Axelstad, M., Dalgaard, M., Boberg, J., Andeasen, H.R., Vinggaard, A.M., 2007. Endocrine-disrupting activities in vivo of the fungicides tebuconazole and epoxiconazole. Toxicol. Sci. 100, 464-473. https://doi.org/10.1093/toxsci/kfm227

Taxvig, C., Vinggaard, A.M., Hass, U., Axelstad, M., Metzdorff, S., Nellemann, C., 2008. Endocrine-disrupting properties in vivo of widely used azole fungicides. Int. J. Androl. 31, 170-177. https://doi.org/10.1111/j.1365-2605.2007.00838.x

Vinggaard, A.., Hnida, C., Breinholt, V., Larsen, J.., 2000. Screening of selected pesticides for inhibition of CYP19 aromatase activity in vitro. Toxicol. Vitr. 14, 227-234. https://doi.org/10.1016/S0887-2333(00)00018-7

Vinggaard, A.M., Christiansen, S., Laier, P., Poulsen, M.E., Breinholt, V., Jarfelt, K., Jacobsen, H., 
Dalgaard, M., Nellemann, C., Hass, U., 2005. Perinatal exposure to the fungicide prochloraz feminizes the male rat offspring. Toxicol. Sci. 85, 886-897. https://doi.org/10.1093/toxsci/kfi150

Vinggaard, A.M., Nellemann, C., Dalgaard, M., Jorgensen, E.B., Andersen, H.R., 2002. Antiandrogenic effects in vitro and in vivo of the fungicide prochloraz. Toxicol. Sci. 69, 344353. https://doi.org/10.1093/toxsci/69.2.344

Welsh, M., Saunders, P.T.K., Fisken, M., Scott, H.M., Hutchison, G.R., Smith, L.B., Sharpe, R.M., 2008. Identification in rats of a programming window for reproductive tract masculinization, disruption of which leads to hypospadias and cryptorchidism. J. Clin. Invest. 118, 1479-90. https://doi.org/10.1172/JCI34241

WHO, 1996. Pesticide residues in food - 1995 evaluations. Part II - Toxicological and Environmental. https://doi.org/nos 889-910 on INCHEM

Zarn, J.A., Bruschweiler, B.J., Schlatter, J.R., 2003. Azole fungicides affect mammalian steroidogenesis by inhibiting sterol 14 alpha-demethylase and aromatase. Environ. Health Perspect. 111, 255-261. https://doi.org/10.1289/ehp.5785

Zhang, W., Ramamoorthy, Y., Kilicarslan, T., Nolte, H., Tyndale, R.F., Sellers, E.M., 2002. Inhibition of cytochromes P450 by antifungal imidazole derivatives. Drug Metab. Dispos. 30, 314-8. https://doi.org/10.1124/DMD.30.3.314

Zheng, Z., Armfield, B.A., Cohn, M.J., 2015. Timing of androgen receptor disruption and estrogen exposure underlies a spectrum of congenital penile anomalies. Proc. Natl. Acad. Sci. U. S. A. 112, E7194-203. https://doi.org/10.1073/pnas.1515981112 
632

633

634

635

636

637

638

639

640

641

642

643

644

645

646

647

648

649

650

651

652

653

654

\section{FIGURE LEGENDS}

Fig. 1: Flusilazole and triticonazole are androgen receptor (AR) antagonists in vitro: Doseresponse curves for flusilazole and triticonazole in the AR-EcoScreen ${ }^{\mathrm{TM}}$ assay. A) Cells were incubated with increasing concentrations of flusilazole or triticonazole $(\mu \mathrm{M})$ in the presence of 0.1 $\mathrm{nM}$ R1881. The values are mean $\pm \operatorname{SEM}(\mathrm{n}=3)$ and are presented as fold change in firefly luminescence relative to R1881 response. B) Cells were incubated with increasing concentrations of flusilazole or triticonazole alone or triticonazole in the presence of $1 \mu \mathrm{M}$ hydroxyflutamide (OHF) $(\mu M)$. The values are mean \pm SEM ( $n=3$ for flusilazole and $n=2$ for triticonazole) and are presented as fold change in firefly luminescence. C) Induction of cytotoxicity following flusilazole exposure, and D) Induction of cytotoxicity following triticonazole exposure. $\mathrm{C}=$ cytotoxicity. The values are mean $\pm \operatorname{SEM}(n=3)$ and are presented as fold change in Renilla luminescence. ${ }^{*} \mathrm{p}<0.05$.

Fig. 2: Triticonazole and flusilazole disrupt steroidogenesis in vitro: Relative steroid hormone levels synthesized by H295R (CRL-2128 $\left.{ }^{\mathrm{TM}}\right)$ cells exposed to increasing concentrations $(\mu \mathrm{M})$ of $\left.\mathrm{A}\right)$ flusilazole or B) triticonazole for 48 hours. HSD = hydroxysteroid dehydrogenase. Data are represented as mean $\pm \operatorname{SEM}(n=3) . * p<0.05$.

\section{Fig. 3: Triticonazole and flusilazole levels in amniotic fluid and fetal plasma: Concentration} $(\mu \mathrm{M})$ of $\mathrm{A})$ triticonazole and B) flusilazole in amniotic fluid or combined plasma from male and female fetuses at GD21. Fetuses were exposed via mothers from GD7-21 to 15 or $45 \mathrm{mg} / \mathrm{kg}$ bw/day of flusilazole or to 150 or $450 \mathrm{mg} / \mathrm{kg}$ bw/day of triticonazole. Controls were zero (data not shown). Results shown are mean \pm SEM of pooled samples from 4 litters. 
655

656

657

658

659

660

661

662

663

664

665

666

667

668

669

670

671

672

673

674

675

Fig. 4: Fetal exposure to triticonazole induces shorter male anogenital distance: The anogenital distance index (AGDi, AGD/cube root of bw) of control males (Control) and flusilazole (15 and 45 $\mathrm{mg} / \mathrm{kg}$ bw/day) or triticonazole (150 and $450 \mathrm{mg} / \mathrm{kg}$ bw/day) exposed males. Results are shown as a box and whiskers plot with the minimum, the 25 th percentile, the median, the 75 th percentile, and the maximum of the data, $\mathrm{n}=7-8$ litters/group. $* \mathrm{p}<0.05$, $* * * \mathrm{p}<0.0001$ (with bw as covariate).

\section{Fig. 5: Flusilazole affects androstenedione and estrone levels in fetal male plasma:}

Fetal male plasma hormone concentrations at GD21 (ng/mL) following exposure to 15 or $45 \mathrm{mg} / \mathrm{kg}$ bw/day of flusilazole or to 150 or $450 \mathrm{mg} / \mathrm{kg}$ bw/day of triticonazole from GD7-21. Results shown are mean \pm SEM of pooled samples from 7-8 litters $(n=7-8)$.

(1)


Table 1 - Internal concentrations of flusilazole and triticonazole

Data represent group means \pm SEM 1 hour \pm 15 min.after exposure

Fluz-15 and Fluz-45 = 15 and 45 mg/kg bw/day flusilazole. Triz-150 and Triz-450 = 150 and 450 mg/kg bw/day triticonazole

\begin{tabular}{lccccc}
\hline & $\begin{array}{c}\text { Control } \\
(\boldsymbol{\mu} \mathbf{M})\end{array}$ & $\begin{array}{c}\text { Fluz-15 } \\
(\boldsymbol{\mu M})\end{array}$ & $\begin{array}{c}\text { Fluz-45 } \\
(\boldsymbol{\mu M})\end{array}$ & $\begin{array}{c}\text { Triz-150 } \\
(\boldsymbol{\mu} \mathbf{M})\end{array}$ & $\begin{array}{c}\text { Triz-450 } \\
(\boldsymbol{\mu} \mathbf{M})\end{array}$ \\
\hline GD21 Caesarean section & & & & & \\
\hline Amniotic Fluid $(\mathrm{N}=4)$ & 0 & $0.20 \pm 0.05$ & $0.59 \pm 0.13$ & $1.34 \pm 0.17$ & $2.98 \pm 1.01$ \\
\hline Male and female plasma $(\mathrm{N}=8)$ & 0 & $0.68 \pm 0.11$ & $2.11 \pm 0.35$ & $5.26 \pm 0.74$ & $9.01 \pm 1.76$ \\
\hline
\end{tabular}

Table 2 - Pregnancy and litter data

Data represent group means, based on litter means \pm SD.

686

Fluz-15 and Fluz-45 = 15 and $45 \mathrm{mg} / \mathrm{kg}$ bw/day flusilazole. Triz- 150 and Triz- $450=150$ and $450 \mathrm{mg} / \mathrm{kg}$ bw/day triticonazole

\begin{tabular}{|c|c|c|c|c|c|}
\hline & Control & Fluz-15 & Fluz-45 & Triz-150 & Triz-450 \\
\hline \multicolumn{6}{|l|}{ GD21 Caesarean section } \\
\hline No. of litters & $\mathrm{N}=8$ & $\mathrm{~N}=8$ & $\mathrm{~N}=8$ & $\mathrm{~N}=7$ & $\mathrm{~N}=8$ \\
\hline Maternal bw (g), GD7 & $245.3 \pm 31.5$ & $243.5 \pm 15.9$ & $236.8 \pm 29.1$ & $245.1 \pm 23.2$ & $246.6 \pm 25.3$ \\
\hline Maternal bw gain $(\mathrm{g})$, GD7-21 & $115.6 \pm 12.3$ & $131.7 \pm 6.6$ & $113.6 \pm 13.7$ & $135.3 \pm 24.6$ & $118.2 \pm 26.2$ \\
\hline Adjusted maternal bw (g), GD21 ${ }^{\mathrm{a}}$ & $281.5 \pm 25.6^{\mathrm{b}}$ & $275.7 \pm 20.5$ & $257.8 \pm 21.7$ & $285.2 \pm 27.9$ & $275.9 \pm 36.1$ \\
\hline No. of implantations & $14.5 \pm 1.5$ & $15.1 \pm 1.0$ & $14.4 \pm 2.4$ & $16.1 \pm 2.0$ & $15.0 \pm 2.4$ \\
\hline No. of fetuses & $13.4 \pm 1.6$ & $14.1 \pm 1.6$ & $13.1 \pm 2.5$ & $16.0 \pm 2.2$ & $14.3 \pm 2.7$ \\
\hline$\%$ postimplantation loss & $7.8 \pm 5.9$ & $6.7 \pm 7.1$ & $8.6 \pm 8.7$ & $2.7 \pm 5.0$ & $5.2 \pm 5.8$ \\
\hline$\%$ late resorptions & $0.8 \pm 2.2$ & $0.8 \pm 2.36$ & $4.3 \pm 8.1$ & $0.9 \pm 2.4$ & $5.2 \pm 5.8$ \\
\hline Fetal bw male (g) & $4.2 \pm 0.3$ & $4.5 \pm 0.4$ & $4.4 \pm 0.3$ & $4.2 \pm 0.4$ & $4.2 \pm 0.3$ \\
\hline Fetal bw female $(\mathrm{g})$ & $4.0 \pm 0.2$ & $4.3 \pm 0.3$ & $4.0 \pm 0.4$ & $3.9 \pm 0.3$ & $4.0 \pm 0.2$ \\
\hline Male AGD (mm) & $4.0 \pm 0.1$ & $4.1 \pm 0.2$ & $4.0 \pm 0.3$ & $3.9 \pm 0.2$ & $3.6 \pm 0.1 * *$ \\
\hline Male AGD index & $2.5 \pm 0.1$ & $2.5 \pm 0.1$ & $2.5 \pm 0.1$ & $2.4 \pm 0.1^{*}$ & $2.3 \pm 0.1 * * *$ \\
\hline Female AGD (mm) & $2.2 \pm 0.1$ & $2.3 \pm 0.2$ & $2.3 \pm 0.1$ & $2.2 \pm 0.1$ & $2.3 \pm 0.1$ \\
\hline Female AGD index & $1.4 \pm 0.1$ & $1.4 \pm 0.1$ & $1.4 \pm 0.1$ & $1.4 \pm 0.1$ & $1.5 \pm 0.1$ \\
\hline
\end{tabular}

694 Values in bold are statistically significantly different from Control

* Significantly different from Control, $\mathrm{p}<0.05$

${ }^{* *}$ Significantly different from Control, $\mathrm{p}<0.001$

**** Significantly different from Control, $\mathrm{p}<0.0001$

${ }^{\text {a }}$ Adjusted maternal bw (g) is bw at GD 21 after subtracting the uterus weight

${ }^{\mathrm{b}} \mathrm{N}=7$ dams, as one uterus was not weighed.

AGD (mm) was analysed with fetal weight as covariate.

AGD index = AGD divided by cube root of the bodyweight 


\section{HIGHLIGHTS}

- Flusilazole and triticonazole have endocrine disrupting activities

- In vitro effects don't fully predict flusilazole and triticonazole in vivo effects

- Triticonazole displays anti-androgenic properties

- Flusilazole exposure reduces estrogen synthesis, likely by aromatase inhibition 


\section{Declaration of interests}

$\bigotimes$ The authors declare that they have no known competing financial interests or personal relationships that could have appeared to influence the work reported in this paper.

$\square$ The authors declare the following financial interests/personal relationships which may be considered as potential competing interests: 

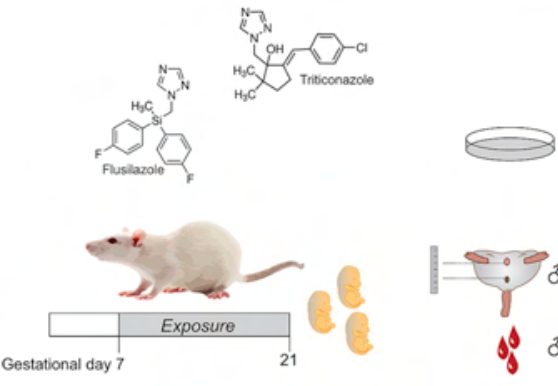

\begin{tabular}{|l|l|}
\hline In vitro & Fism \\
\hline AR Antagonism & \\
\hline AR Agonism & \\
\hline $\begin{array}{l}\text { Steroidogenesis } \\
\text { Disruption }\end{array}$ & \\
\hline
\end{tabular}

In vivo

Anogenital

Distance

Androstenedione

Estrone 

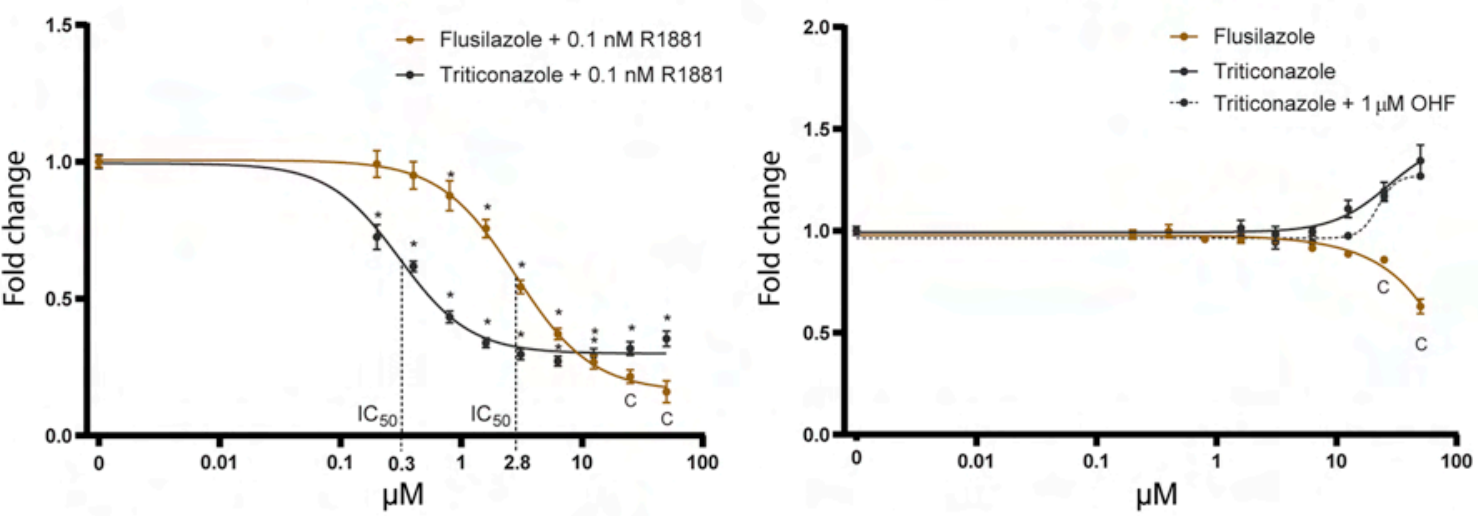

C Flusilazole cytotoxicity

D Triticonazole cytotoxicity
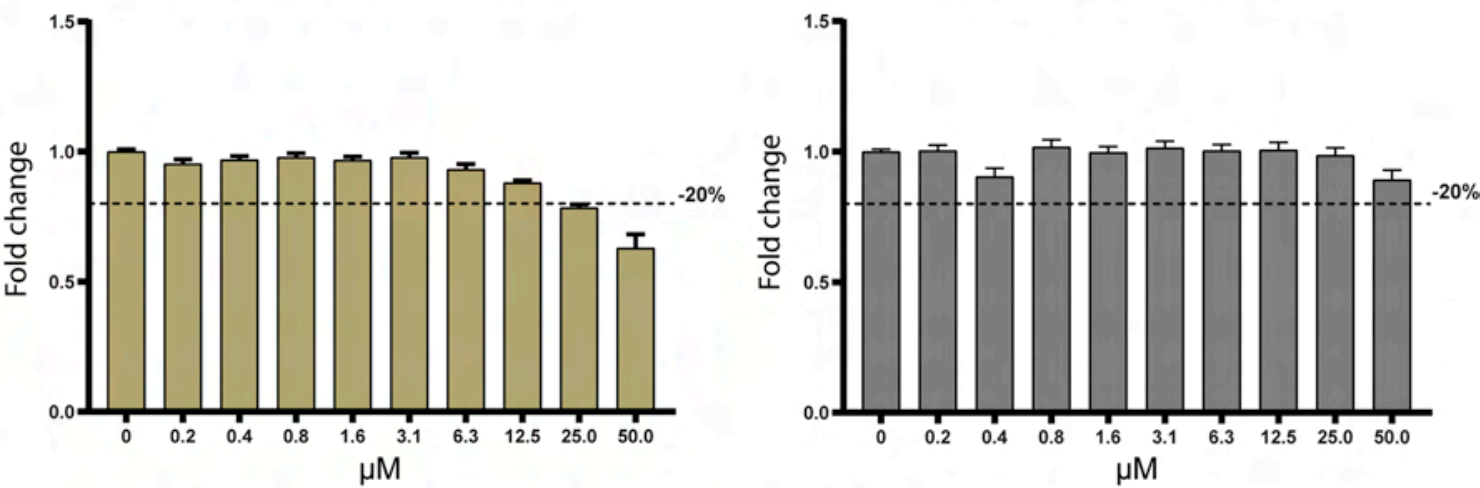


\section{Triticonazole}

Flusilazole
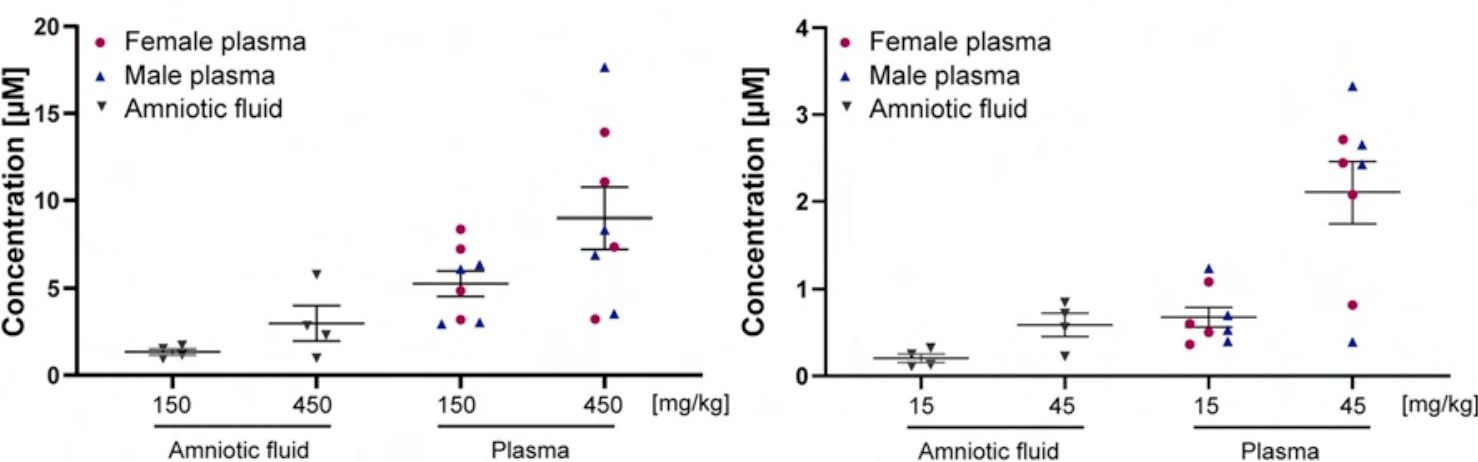


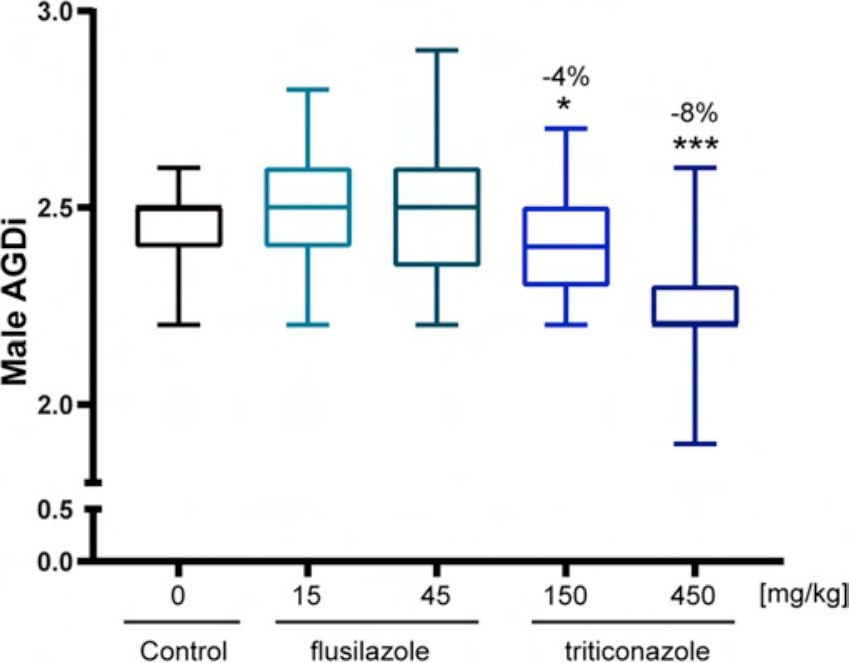


